\title{
O horizonte ético-ontológico da relação dialógica: filosofia e diálogo inter-religioso
}

\author{
Marta Luzie de Oliveira Frecheiras
}

\section{Resumo}

O objetivo primordial desta comunicação é procurar clarificar alguns conceitos filosóficos fundamentais sem os quais não há diálogo e, sim, monólogo. Basicamente, trataremos dos conceitos de juízo, juízo axiológico e juízo de realidade; o conceito de verdade, bem como os conceitos metafísicos de ôntico-ontológico e, por fim, as noções centrais, e que, frequentemente vêm a nós permeadas de confusão semântico-conceitual, que são: ética e moral.

O segundo objetivo desta comunicação, já dentro da dinâmica da moralidade, e, portanto, da Ética, é apresentar alguns pressupostos centrais para uma vida humana digna de ser nomeada como tal, como por exemplo: respeito à dignidade da vida em geral e, em particular, da vida humana.

O terceiro objetivo é defender a hipótese teórica que afirma o fato de o conceito de verdade não dizer respeito à dimensão epistemológica da realidade e, sim, ontológica.

O método para validar tal intento perpassará dois momentos distintos. Se possível, durante a análise conceitual, far-se-á uma breve incursão etimológica e também procuraremos apresentar, vez por outra, a origem filosófica do termo. Não caberá aqui estabelecer a evolução semântica de cada conceito porque sobrepassaria os limites desta comunicação. 
Palavras-chave: Juízo, Axiologia, Verdade, Ontologia.

\begin{abstract}
The primary aim of this communication is to clarify some fundamental philosophical concepts without which there is no dialogue but rather, a monologue. Basically, the following will be discussed: concepts of judgement, axiological judgement and judgment of reality; the concept of truth, as well as the metaphysical concepts of ontic-ontology and, finally, central notions, which often provoke semantic-conceptual confusion, which are: ethics and morality.

The second objective of this communication, within the dynamics of morality, and, therefore, of ethics, is to present some core presuppositions for human life deserving to be named as such, for example: respect for the dignity of life in general and, in particular, human life.

The third objective is to defend the theoretical hypothesis that states the fact that the concept of truth does not relate to the epistemological dimension of reality but rather, the ontological.

The method to validate such intent will pervade two distinct eras. If possible, during the conceptual analysis, a brief etymological examination will be made and an attempt to present the philosophical origin of the term. It is not possible to establish the semantic evolution of each concept because the limits of this account will be surpassed.
\end{abstract}

Keywords: Judgement, Axiology, Truth, Ontology.

\title{
1. Clarificando Conceitos
}

\subsection{Juízo}

É o corolário natural da ação de ajuizar ou de julgar. Em filosofia, ajuizar é afirmar ou negar algo sobre algo (S é P) ${ }^{1}$. Pressupõe, neste sentido, um sujeito e um objeto, pressupõe a vigência de diferentes, e que o sujeito deverá descrever o objeto sobre o qual ele irá, posteriormente, ajuizar.

A questão central está no fato de que antes de ajuizar, o sujeito tem que descrever o estado de coisas, deve dizer primeiramente o que a coisa é, para,

\footnotetext{
${ }^{1}$ A fórmula "sujeito é predicado", uma vez que o juízo é o ato pelo qual o espírito compõe ao afirmar e divide ao negar.
} 
num segundo momento, afirmar algo sobre ela. É a distinção entre conceito e juízo em Lógica Filosófica. O conceito é o nome da coisa, o juízo é uma afirmação ou negação acerca desta coisa.

Afirmar o estado de coisas é sempre uma afirmação sobre algo cuja dimensão é objetiva, isto é, algo que é passível de ser apreendido pelos cinco sentidos e que se encontra numa coordenada de tempo e de espaço. É algo universalmente acessível, é acessível a todo e qualquer ser humano, a menos que o sujeito não esteja na mesma coordenada de tempo e espaço do objeto.

A dimensão objetiva radica a sua origem etimológica na palavra latina ob-jectum, que, por sua vez, significa "jogado, lançado diante de alguém": o sujeito. O prefixo " $o b$ " marca a distinção: " $o b$ " é o mesmo que "diante de".

Já o prefixo $s u b$ é a tradução latina do prefixo grego uJpov, hypó, que quer dizer "embaixo de". É o prefixo das palavras portuguesas substrato, subjacente, subliminar, dentre outras. Refere-se a algo recôndito, que não é passível de ser visto. Sendo assim, subjectum, sujeito, remete-nos ao "estar jogado por baixo de", ou melhor, dentro de. Trata-se da interioridade subjacente ao sujeito humano

Distintamente do conceito, o juízo tem uma dimensão subjetiva uma vez que ele não é a mera descrição do status quo, mas sim, uma afirmação ou negação do sujeito acerca do objeto. Como a centralidade do juízo consiste na afirmação ou negação do sujeito, ela pode ser falsa ou verdadeira.

\subsection{Juízo Axiológico}

O termo "axiologia" provém da palavra grega a]xio", que na transliteração latina redunda em áxios. Áxios é aquilo que é valoroso, que tem valor de, que é digno. A axiologia, portanto, é o ramo da Filosofia que reflete acerca do que é desejável por si mesmo, independente dos interesses particularistas². Um juízo axiológico, ou de valor, é uma afirmação ou negação do valor de algo, é uma afirmação ou negação que remete à essência daquilo que se valora. No entanto, no quotidiano, não é isso que verificamos. Na maioria das vezes, ajuizar passa a ser o mesmo que afirmar ou negar algo sobre algo a partir do "meu" interesse e das "minhas" perspectivas e hábitos e costumes culturais, afetivos, vivenciais, dentre outros, perdendo assim, a relação com o tema da verdade.

A nódoa basilar da questão do valor é que, mormente, o sujeito ajuíza axiologicamente a partir daquilo que lhe agrada ou desagrada, ou seja, a partir

${ }^{2}$ Cf. AUDI, Robert (dir). “Teoria do Valor”. In: Dicionário de Filosofia de Cambridge. Paulus, São Paulo, 2006, pp. 931-932. 
do interesse privado e, não, do interesse público, a partir do sum-pavQo" e do ajnti-pavqo". A palavra grega páthos quer dizer paixão, mas não no sentido que compreendemos hodiernamente de forte emoção, mas no senso de passividade. A palavra latina para páthos é affectio-ônis, que quer dizer efeito, impressão, influência. Páthos significa "ser afetado", padecer ${ }^{3}$. Por esta razão, como a afetividade é uma impressão que ocorre na interioridade do sujeito, é extremamente difícil que o mesmo consiga transcender a sensibilidade para projetar-se em algo que está para além dele mesmo e avaliar, isto é, ajuizar axiologicamente segundo uma regra de universalidade e não, segundo uma regra privada.

\subsection{Juízo de Realidade}

O que chamamos aqui através da fórmula "juízo de realidade" é tanto a definição greco- romana como tomista de verdade: veritas est adaequatio intellectus ad rem, caracterizando a metafísica da objetividade, bem como a definição do mesmo conceito de verdade para alguns pensadores modernos, contemporâneos e pós-modernos: veritas est adaequatio rei et intellectus, a assim chamada metafísica da subjetividade.

Posto isso, o juízo de realidade é a afirmação ou negação acerca da verificação da veracidade ou da falsidade entre nome e coisa. Ao longo da história da tradição metafísica, muito se discutiu em torno da prioridade epistemológica, se esta caberia ao ser humano e, portanto, ao intelecto, à subjetividade, ou se o predomínio caberia às coisas, ao real, à objetividade. $\mathrm{O}$ fato é que o juízo de realidade é o ato de afirmar ou negar se a assertiva lógica corresponde ao real, ao factual. Logo, ele é ou verdadeiro ou falso.

\subsection{O Conceito de Verdade: Acerca da dimensão ôntico-ontológica}

Pretendemos defender aqui a hipótese de que o conceito filosófico de verdade, surgido dentre os pensadores pré-socráticos ${ }^{4}$, foi, paulatinamente, ganhando contorno epistemológico. Já apareciano proêmio de Parmênides

\footnotetext{
${ }^{3}$ Padecer não é o mesmo que sofrer. Sofrer é aquilo que fazemos com o padecer, diz respeito ao "como" padecemos. Não é uma pergunta pelo "quê" (padecer), mas pelo "como" (sofrer, passar pela dor de modo negativo). Não se trata de uma questão objetiva, mas subjetiva.

${ }_{4}^{4}$ SIMPLÍCIO. "De Caelo". In: KIRK, G. S. \& RAVEN, J. E. \& SCHOFIELD. Os Filósofos Pre-socráticos. 4a . edição, Fundação Calouste Gulbenkian, Lisboa, 1994, pp.252.
} 
(séculos VI - V a.C.), que nos foi legado por Simplício em seu Caelo 557, 25 e ss. No verso de número vinte e nove aparece os seguintes termos gregos: ajlhqeivh" eujkuklevo" que em português quer dizer "a verdade bem redonda".

Esta confusão conceitual é a causa de grandes equívocos não só ao longo da história do ocidente, bem como na atualidade, acarretando com isso cortes epistemológicos, que em termos de vida humana levam a afastamentos, brigas, dissensões e desarmonia.

Vimos no verbete anterior que o "juízo de realidade" expressa que tal assertiva é ou verdadeira ou falsa. Verdadeiro é uma qualidade da proposição que está adequada à coisa, à realidade. Mas será que a verdade é o verdadeiro? $\mathrm{O}$ verdadeiro não é apenas a qualidade de uma proposição que é simplesmente uma expressão humana? Podemos afirmar que está conforme a lei da razão reduzir toda a dinamicidade da realidade à proposição, à assertiva humana?

Essa pergunta já foi respondida por Immanuel Kant, filósofo alemão do século XVIII. Este pensador é um marco na história da Filosofia. Não é mais possível pensar excluindo as considerações propostas por Kant. E por quê? Porque Kant vai estabelecer em sua Crítica da Razão Pura os limites para o uso da Razão humana: quais são as suas capacidades e as suas impossibilidades. Nesta obra, no artigo quarto das Observações Gerais sobre a Estética Transcendental, ele nos afirma que a intuição é intuitus derivatus. ${ }^{5}$

O que isto significa? Significa que o sujeito cognoscente, por possuir a faculdade da sensibilidade, isto é a capacidade de ser afetado pelo objeto e de receber as impressões sensíveis provenientes desse mesmo objeto, é capaz de percepcioná-lo.

No entanto, para que isto ocorra, é imprescindível que o objeto esteja diante do sujeito cognoscente. Faz-se necessário que tanto o sujeito como objeto estejam um diante do outro no mesmo lugar e ao mesmo tempo. A isso ele denominou de "intuição derivada": Derivada porque depende da presença do objeto diante do sujeito, que por sua vez, não é capaz de fazer com que os objetos estejam diante dele na hora que ele quiser para poder percepcioná-los, pois é a partir daí que o conhecimento tem início e somente aí.

Kant afirma que a razão humana é capaz de conhecer o objeto, a dimensão ôntica da realidade, composta por indivíduos materiais, sejam seres humanos, produtos da ação humana ou natureza e que possuam um contorno físico que o

\footnotetext{
${ }^{5}$ KANT, Immanuel. “Crítica da Razão Pura”. In: Domínio Público, Portal Capes, pp. 30. Disponível em: http://www.dominiopublico.gov.br/download/texto/cv000016.pdf. Acesso em 14 de agosto de 2011.
} 
individualizem. Objeto, pois, é a coisa concreta, o indivíduo concreto passível de ser apreendido pelos cinco órgãos sensoriais. O que não é objetal pode ser pensado, mas não conhecido.

Porém, não poder ser conhecido não significa dizer que não exista. Não existe como coisa, mas isso não extingue o seu ser, a sua possibilidade de ser.

Aristóteles, em sua Metafisica ${ }^{6}$ já havia afirmado que o to; o[n, ens em latim, ente, em português, possui duas dimensões: uma substancial a que ele denominou de oujsiva, substância, e uma dimensão categorial, kategoriaiv. O que Aristóteles chamou de ousía é o que tentamos aqui interpretar como dimensão ontológica da realidade e as kategoriaí como a dimensão ôntica da mesma.

Martin Heidegger, filósofo do século XX, procurou tematizar este problema a partir de sua obra inaugural Sein und Zeit. Nela, ele já começa a demonstrar que o ser (dimensão ontológica), distintamente do ente (dimensão ôntica) possui a sua dinamicidade aliada ao tempo: o ser se dá no tempo.

Em Beiträge zur Philosophie ele afirma que a dinâmica própria do Seyn ${ }^{7}$ é o Ereignis, é o acontecer. O ser, pois, acontece. Acontecer, porém, não quer dizer apenas tornar-se ente, individualizar, mas também, diz vir à luz, aparecer, manifestar-se, do grego faivnw. E, nem tudo que se manifesta é ôntico.

A questão do ser, para Heidegger, transcende a realidade ôntica do ente. A realidade ôntica é apreendida universalmente, pois é captada pelos cinco sentidos, por isso, ao longo da história da humanidade sobre a terra, procurou-se aumentar o conhecimento humano acerca dos entes, das coisas, da natureza. Basicamente, é um olhar para fora, conhecer o que é diferente de nós.

No entanto, o ser não se mostra plenamente e o tempo todo como o ente o faz, porque ele é tempo. Isto não invalida, porém, a possibilidade de que nós possamos pressenti-lo. Exige uma escuta arguta, exige e clama pelo pensar que sabe que não irá instrumentalizar, manipular, controlar, dominar, reter. Mas não é por isso, que é algo de somenos.Compõe a dinamicidade do ser, a sua propriedade mais própria: a vigência da liberdade. A vida não é o que nós queremos que ela seja. Ela simplesmente é. Por mais que estejamos insatisfeitos com a realidade em torno de nós, ela não mudará como num toque de mágica, ainda que tenhamos e vivamos "sonhando", fantasiando essa possibi-

\footnotetext{
${ }^{6}$ ARISTÓTELES. Metafísica. Edición Trilingüe. Tradução: Valentín García Yebra. Editorial Gredos, Madrid, 1987. Z 2, 25-30, pp. 322.

${ }^{7}$ Cf. HEIGDEGGER, Martin. “Beiträge zur Philosophie(Vom Ereignis)”. In: Gesamtausgabe:Band 65, Vittorio Klostermann, Frankfurt am Main, 1994, pp. 239. Tradução portuguesa em letra maiúscula "Ser".
} 
lidade. Outrora tínhamos a hermenêutica mítica da realidade, hoje, temos em alguns casos, as fórmulas medicamentosas.

Com isso não estabelecemos um juízo moral, apenas queremos reiterar que a vida tem a sua dinâmica própria de tempo. E os gregos sabiam disso. Através do termo kairov", os gregos expressavam a compreensão de tempo propício, de tempo próprio.

Heidegger em sua obra intitulada Einführung in die Metaphysik afirma8:

Es ist völlig richtig und in der besten Ordnung: "man kann mit der Philosophie nichts anfangen". Verkehrt ist nur, zu meinen, damit sei das Urteil über die Philosophie beendet. Es kommt nähmlich noch ein kleiner Nachtrag in der Gestalt einer Gegenfrage, ob, wenn schon wir mit ihr nichts anfangen können, die Philosophie am Ende nicht mit uns etwas anfängt, gesetzt dass wir uns auf sie einlassen.

Nesta passagem, como também em Sein und Zeit, Heidegger demarca terreno na antropologia filosófica. Ele desloca o problema do ente. Da dimensão epistemológica, ele o encaminha para a dimensão ontológica e antropológica, originando assim, a questão da autenticidade e da inautenticidade. A mesma problemática da diferença ontológica, ou seja, da diferença entre ente e ser, Heidegger a translada para a antropologia. O que é então a dimensão ôntico-ontológica no ser humano? A dimensão ôntica descreve o simples fato de estarmos no mundo. O Homem é um in-der-Welt-sein ${ }^{9}$ e o modo mais corriqueiro de ser no mundo, é ser no impessoal, a palavra alemã Man.

$\mathrm{O}$ "a gente" representa o modo de ser "como todos e ninguém ao mesmo tempo". Caracteriza o fato de, mormente, já estarmos imersos num mundo, isto é, numa dada cultura com seus costumes, hábitos, ideologias e visões de mundo. Para Heidegger, mundo é sempre mundo espiritual ${ }^{10}$, mundo significa potencialidades, possibilidades humanas. Onde há uma visão de mundo dominante e globalmente forte, o espírito se desvanece e o mundo se cristaliza,

\footnotetext{
${ }^{8}$ HEIDEGGER, Martin. Einführung in die Metaphysik. Max Niemeyer Verlag, Tübingen, 1953, pp.9-10.

Tradução nossa:

É certo e na melhor ordem dizer: "Com a filosofia nada se pode começar". Errado é pensar somente que com isso o juízo sobre a filosofia terminou. Vem ainda um pequeno acréscimo na figura de uma contra-pergunta, se nós não podemos começar nada com ela, ao fim a filosofia não começa algo conosco se nos travarmos relações com ela?

${ }^{9}$ Ser no mundo.

${ }^{10}$ Cf. Id. Ser e Tempo. 4a ${ }^{\text {a }}$ Edição, Vozes, Petrópolis, 2006, pp.561-598.
} 
depauperando-se. Sendo assim, o Homem não conhece a verdade, mas pode vivê-la e, deste modo, encontrá-la. Por isso, não se trata de um problema de ordem cognoscitiva, mas sim de uma questão na ordem ontológica.

\section{5. Ética, Eticidade, Moralidade e Moral}

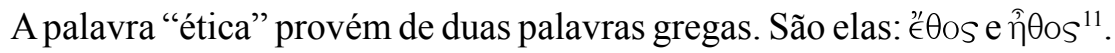
Em Homero, "̈ $\theta$ os tem sua origem em $\epsilon " \omega \theta \alpha$, o antigo perfeito intransitivo que quer dizer "ter o hábito de". Era frequentemente empregado no particípio, ressaltando assim, o sentido de "estar habituado", de "estar acostumado". Já a palavra grega $\hat{\eta} \theta 0 s$, tanto em Homero, como em Hesíodo, significava a "maneira de ser", o "modo de ser", o "caráter", ou seja, as características da pessoa. Estabelecendo um paralelo entre estes termos gregos e os conceitos heideggerianos supracitados, o e[qo" explicitaria a dimensão antropológica ôntica e, portanto, inautêntica; enquanto o $\hat{\eta} \theta$ os ressaltaria a dimensão ontológica e autêntica do ser humano.

Quando houve a tradução para a língua latina, ela ocorreu através do termo mos, moris que significava num primeiro sentido, o modo de proceder não de acordo com a lei, mas de acordo com os costumes e, num segundo sentido, o modo, a maneira de ser. ${ }^{12}$

Desta feita, através da etimologia e da semântica dos termos, podemos depreender que o que em grego era expresso através de dois termos distintos, em latim ficou circunscrito a um único termo.

Porém, em Filosofia, a duplicidade terminológica permaneceu e, de modo algum, é motivo de consenso entre os filósofos morais ${ }^{13}$. O fato é que há duplas funções significativas pensadas pela Filosofia a partir dos diversos autores. No nosso caso, argumentaremos apenas a partir de Friedrich Hegel, por considerarmos que ele buscou resgatar o sentido original dos termos gregos, através do destaque dado aos termos alemães: Moralität e Sittlichkeit.

A Filosofia moral de Hegel também está circunscrita à sua filosofia da história e à filosofia do espírito. Neste sentido, moralidade é um momento do

\footnotetext{
${ }^{11}$ Cf. CHANTRAine, Pierre. “ $\in l \omega \theta a-\eta \hat{\theta} \theta$ os”. In: Dictionnaire Étymologique de la Langue Grecque. Klincksieck, Paris, 1999. pp 327 e 407 respectivamente.

${ }^{12}$ Cf. FERREIRA, António Gomes. "Mos, moris”. In: Dicionário de Latim-Português. Porto Editora, Porto, 1988, pp.741.

${ }^{13}$ Cf. CANTO-SPERBER, Monique. "Ética”. Dicionário de Ética e Filosofia Moral. Volume 1. Editora Unisinos, São Leopoldo, 2007, pp. 591.
} 
desenvolvimento conceitual do espírito ${ }^{14}$. Diz respeito à etapa de maturação da auto-compreensão de si mesmo (espírito), do individual na coletividade. Quando o espírito chega nesse nível de maturidade, da indelével compreensão de que faz parte de um todo, de que cada ação sua reflete o todo e no todo, ele compreende a moralidade, a compreensão de que o espírito é livre e deve ser respeitado coletivamente como tal. A moralidade ou moral em Hegel é o tempo da maturidade em que a pluralidade se percebe na unidade.

Já a Sittlichkeit, a eticidade ou a ética representa uma vida que se realiza de uma maneira orgânica ${ }^{15}$, uma vida que procura realizar-se harmonicamente, engendrando na individualidade o reconhecimento da necessidade de conciliação dos opostos ${ }^{16}$. Neste sentido, um juízo moral em Hegel é aquele que afirma ou nega até que ponto um indivíduo ou grupo social agem moralmente, isto é, tendo em vista o bem da coletividade.

Peter Singer é um filósofo contemporâneo australiano, utilitarista que nos premia com um exemplo de vida moral, segundo Hegel. Para ele, seguindo os passos de John Rawls, a personalidade moral constitui a base da igualdade humana e esta, por sua vez, não é outra coisa senão a justiça ${ }^{17}$.

Ele torna o conceito de moral sinônimo de ética, quando esta última é prática, quando a ética deixa de ser um mero discurso teorético para atuar efetivamente de modo a pensar no bem comum. Ele dá ótimos exemplos que nos causam espanto, pois ele é especialista em tratamento de animais não humanos e na erradicação da pobreza no mundo, no alívio da fome.

Tomemos as nossas conclusões sobre o uso de animais para a produção de alimentos, ou sobre a ajuda que os ricos deveriam dar aos pobres. Alguns leitores podem aceitar essas conclusões, tornando-se vegetarianos e passando a fazer tudo o que esteja ao seu alcance para reduzir a pobreza absoluta. ${ }^{18}$

O pressuposto básico do qual partimos é de que o princípio de que todos os seres humanos são iguais faz parte da ortodoxia ético-política dominante. Porém, este pressuposto é falso, posto que alguns seres humanos são brancos, outros negros; alguns são altos, outros baixos; alguns são ricos, outros pobres;

\footnotetext{
14 "Hegel”. Ibid, pp. 720.

${ }^{15}$ Ibid, pp. 723.

${ }^{16}$ A junção entre costumes aprendidos e modo de ser mais próprio. Em linguagem heideggeriana, a conciliação de inautenticidade com autenticidade.

${ }^{17}$ SINGER, Peter. Ética Prática. Martins Fontes, São Paulo, 2002, pp. 27.

${ }^{18}$ Cf. Ibid, pp. 331.
} 
alguns comem em demasia, outros morrem de inanição; uns são cristãos, outros muçulmanos. Como continuamos falamos ainda de igualdade?

Neste sentido, a igualdade deve ser o ponto ao qual queremos chegar e, não, do qual partir, se realmente queremos viver uma vida moral e justa no mundo hoje. Com esse intuito, para finalizarmos, elencaremos alguns princípios básicos que não podem ser esquecidos para uma vida moral, efetivamente ética e que, possam nortear todo e qualquer diálogo inter-religioso.

\section{Princípios Norteadores ${ }^{19}$}

\subsection{Inclusão}

Não tratar o outro de modo que ele não se sinta incluído no grupo, na comunidade, na instituição, dentre outros. Evitar a compreensão elitista das relações sociais: a visão ressentida da vida, ou seja, ter de diminuir outrem para sentir-se superior.

\subsection{Segurança}

É importante tratarmos o outro de modo que ele não se sinta ameaçado em sua integridade físico-psíquica e emocional. Que o outro se sinta seguro em nossa presença.

\subsection{Justiça}

O outro precisa saber que lidamos com ele a partir do princípio de razoabilidade e de equanimidade, isto é, de modo equilibrado e de acordo com as normas e a legislação vigente.

\subsection{Princípio da autonomia}

O outro necessita sentir-se suficientemente livre na nossa presença para poder atuar por si mesmo, sem dominarmos, sem querermos controlar a sua vida e demonstrarmos que estamos otimistas acerca de sua vida futura. É necessário que o outro saiba que não ultrapassaremos o limite de nossa individualidade.

\footnotetext{
${ }^{19}$ Cf. HICKS, Donna. "La Dignidad en el Perdón: Caminos hacia el Desarrollo emocional". In: NARVÁEZ, Leonel. Cultura política de Perdón y Reconciliación. Fundación para La Reconciliación, Bogotá, 2009, pp. 110-111.
} 


\subsection{Princípio da compreensão}

Dar a liberdade, que é de direito a outrem, para que ele perceba que pode se expressar e expor suas perspectivas e interpretações da vida que será compreendido em sua diferença.

\subsection{Princípio do Benefício da Dúvida}

O princípio do benefício da dúvida explicita que no caso de dúvida, apostemos sempre nas boas intenções dos outros, que não interpretamos aprioristicamente acerca das ações que não estamos suficientemente informados. Não achar de antemão que os outros agiram com dolo.

\subsection{Princípio da Sensibilidade}

Princípio muito importante, pois aqui garantimos que reconhecemos a existência do outro, ainda que emocionalmente sintamos distintamente. Não negar a existência do outro, não fingir que não viu, quando viu. Reconhecer a dignidade da vida do outro como fim em si mesmo e não para nós.

\subsection{Princípio da Responsabilidade}

Por fim, é imprescindível que o outro saiba que somos capazes de reconhecer o nosso erro quando erramos. Não é justo, nem tampouco digno, culpabilizarmos o outro por nossas incapacidades, deficiências e cegueiras. É importante que o outro saiba que reconhecemos que somos os responsáveis pela ferida que causamos nele, que violamos a sua dignidade. A vigência deste princípio é capaz de restaurar imediatamente as relações cindidas, pois aqui, demonstramos toda a nossa humanidade, através da humildade, pelo reconhecimento da nossa "miséria humana".

\section{Considerações Finais}

Todo diálogo pressupõe um encontro. Este, por sua vez, é inesperado. Nós não controlamos a sua dinâmica de conformação. Ele se forma-com e, nesse conformar-se, neste dar forma a algo junto com um outro, podemos ouvir e dizer o que não esperávamos, o que não desejávamos. 
Porém, não podemos entrar num diálogo sem o exercício constante de autocrítica. Esta prática é inalienável, ou nós fazemos ou ninguém mais faz. Por mais que argumentemos, não se consegue convencer o outro a pensar. Ele tem que querer. Pensar dá trabalho, muito trabalho.

É trabalhoso, porque pôr-se em questão, desestrutura; somos levados a um horizonte infinito e sentimos medo, tememos nos perder na imensidão. Trata-se de um exercício que exige uma escolha radical. Podemos perder muito sob o ponto de vista ôntico. Podemos perder bens, pessoas, status, a falsa personalidade, às vezes, até a saúde.

Mas o que preferimos perder: coisas ou nós mesmos. Na estrada da vida caminha-se, e só se pode caminhar ou parar, não se pode pegar atalhos ou trilhas, pois estes inexistem. São apenas ilusões mentais.

Perder a si mesmo é perder em vida, é perder tempo de vida que não retorna mais. Mas quando encontramos a nós mesmos, renascemos, porque encontramos o fio que conduz ao sentido, a uma vida mais plena, mais autêntica e, por isso mesmo, sinceramente livre e de relação fraterna com o outro, com os outros.

O outro, parece-nos perigoso, mas, ao mesmo tempo, nos salva de nós mesmos e das construções teóricas e axiológicas nas quais somos capazes de nos agarrar como tábuas salva-vida. $\mathrm{O}$ outro nos arranca do lugar comum ao qual mormente nos instalamos e não queremos mais sair, afinal de contas, nos adaptamos e, às vezes, até nos regozijamos.

Mas o outro também pode estar alienado de si mesmo e quer impor a sua alienação a nós. Tudo isto requer muito cuidado e cultivo do pensar, não do pensamento, mas do pensar. Pensar é uma atividade e, não, um conteúdo. Pensar é o exercício mais puro da liberdade. Não custa nada, não exige nenhuma técnica e não se conquista adquirindo livros ou arquivando textos em nosso computador, ou através de títulos acadêmicos ou honoríficos. Pensar depende de uma abertura do espírito e do assentimento da vontade. Heidegger descreve a experiência do pensar como um salto no abismo, salto originário (Ur-sprung) ${ }^{20}$

Quando o tema do diálogo é religião, o perigo é maior, pois quase sempre singramos por mares axiológicos. É extremamente difícil transcender os valores aos quais nos agarramos e vivemos mergulhados. É difícil querer viver na proximidade do real, pois ele não é só de nível ôntico, ele é também de nível ontológico, e é aí que o pensar faz a sua morada.

${ }^{20}$ HEIDEGGER, Martin. Einführung in die Metaphysik. Max Niemeyer Verlag, Tübingen, 1953, pp.5. 
Será que durante um diálogo, estamos ocupados e abertos a possível visitação da verdade? Achamos que ela é possível? Por isso tratamos da questão da verdade como sendo uma dinâmica ontológica e, não, uma assertiva, uma afirmação humana.

Aprendemos com Aristóteles que o filosofar tem início com o qauvma ${ }^{21}$, com e a partir do espanto, da admiração, a partir do não-saber, a partir da incerteza. O autômato não se admira, não se espanta mais. Fé não é certeza, nem convicção, fé é a experiência mais originária de abertura do homem ao não-saber. A razão não alcança como conhecimento o que não é objeto, já vimos isso com Kant, mas alcança ontologicamente com o despertar da fé. A palavra razão vem do grego lovgo", que provém do verbo levgw. Légō significa dizer e reunir. Reunir, para nós, tem paralelo com a dimensão ontológica da realidade, enquanto dizer, com a dimensão ôntica. Por isso, que o conhecimento objetivo das coisas, o ôntico, diz o que elas são, enquanto o discurso ontológico é pleno de silêncio e de não-dito. Não significa dizer que algo não possa ser dito, mas não como um conhecimento acabado e conclusivo.

Um encontro é sempre inesperado, mas exige que sejamos capazes de sairmos de nós mesmos, de nossa ipseidade, de nosso mundo egótico, para podermos vislumbrar o que está para além do infinito, que é o outro em sua alteridade mais própria.

\section{Referências Bibliográficas}

\section{Dicionários:}

AUDI, Robert (dir). Dicionário de Filosofia de Cambridge. Paulus, São Paulo, 2006.

BLACKBURN, Simon. Oxford Dictionary of Philosophy. Oxford University Press, Oxford-New York, 1996.

CANTO-SPERBER, Monique. Dicionário de Ética e Filosofia Moral. Volumes 1 e 2. Editora Unisinos, São Leopoldo, 2007.

CHANTRAINE, Pierre. Dictionnaire Étymologique de la Langue Grecque. Klincksieck, Paris, 1999.

FERREIRA, António Gomes. Dicionário de Latim-Português. Porto Editora, Porto, 1988.

${ }^{21}$ ARISTÓTELES. Metafísica. Edición Trilingüe. Tradução: Valentín García Yebra. Editorial Gredos , Madrid, 1987, A 2 983b15, pp. 14. 


\section{Fonte Primária:}

ARISTÓTELES. Metafísica. Edición Trilingüe. Tradução: Valentín García Yebra. Editorial Gredos, Madrid, 1987.

HEIGDEGGER, Martin. "Beiträge zur Philosophie (Vom Ereignis)". In: Gesamtausgabe: Band 65, Vittorio Klostermann, Frankfurt am Main, 1994. HEIDEGGER, Martin. Einführung in die Metaphysik. Max Niemeyer Verlag, Tübingen, 1953.

KIRK, G. S. \& RAVEN, J. E. \& SCHOFIELD. Os Filósofos Pre-socráticos. $4^{\mathrm{a}}$. edição, Fundação Calouste Gulbenkian, Lisboa, 1994.

NARVÁEZ, Leonel. Cultura política de Perdón y Reconciliación. Fundación para la Reconciliación, Bogotá, 2009.

SINGER, Peter. Ética Prática. Martins Fontes, São Paulo, 2002.

\section{Citação Eletrônica:}

KANT, Immanuel. "Crítica da Razão Pura". In: Domínio Público, Portal Capes. Disponível em: <http://www.dominiopublico.gov.br/download/ texto/cv000016.pdf $>$. Acesso em 14 de agosto de 2011.

\section{Marta Luzie de Oliveira Frecheiras}

Bacharel, mestre e doutora em Filosofia pela UFRJ

Pós-doutorado em Filosofia pela Universidad Complutense de Madrid (UCM) Pós-doutorado em Filosofia pela Ludwig-Maximilians-Üniversität München (LMU) Professora Associado I em Filosofia da Universidade Federal de Ouro Preto (UFOP)

Artigo Recebido em 19/08/2011

Artigo Aprovado em 21/11/2011 